\title{
Indiferenciação por diferença
}

Implicações da governamentalidade neoliberal

para a teoria sociológica'

Lucas Trindade da Silva*

http://orcid.org/0000-0003-3390-2046

Introdução

O interesse deste artigo é de ler o diagnóstico do contemporâneo, presente em Nascimento da biopolitica, à luz de um enunciado que perpassa clássicos e contemporâneos da teoria sociológica. Trata-se do enunciado da diferenciação/autonomização das esferas sociais que, articulado aos enunciados da secularização e da individuação, define um aspecto decisivo do discurso sociológico hegemônico sobre a modernidade (Tavolaro, 2007).

No âmbito de um esforço explícito de fundar as ciências sociais e a sociologia, as bases desse enunciado podem ser encontradas, num marco naturalista, nos trabalhos de Herbert Spencer e Émile Durkheim e, num marco hermenêutico e neokantiano,

* Universidade Federal do Rio Grande do Norte, Natal, Rio Grande do Norte, Brasil.

1. Este artigo utiliza, sintetiza, lapida formalmente e desenvolve um dos principais resultados da minha pesquisa de doutorado, que ganhou corpo na tese Biopolitica e o Enunciado da Autonomização das Esferas Sociais (ver Silva, 2018, em particular a seção 3.3). Agradeço especialmente a Sergio B. F. Tavolaro pela sua inspiradora capacidade de formalizar e repensar o discurso sociológico sobre a modernidade, assim como pela formação no exercício aqui buscado de aliar rigor científico e imaginação conceitual. Agradeço a Cynthia Hamlin, Gabriel Peters, Eliane Gonçalves e a todas (os) as (os) integrantes do Grupo de Pesquisa em Teoria Social e Subjetividades (GETss) do Programa de Pós-Graduação em Sociologia da UfPE. Agradeço, nos nomes de Elaine Leite e William Soto, ao Programa de Pós-Graduação em Sociologia da Ufpel. Agradeço, por fim, à disposição sempre generosa de Frédéric Vandenberghe que, inclusive, atentou-me para a necessidade de retornar a Spencer. 
nos trabalhos de Wilhelm Dilthey e Georg Simmel, mas é sobretudo na sociologia da religião de Max Weber que um discurso sobre a diferenciação social como um processo de delimitação das legalidades intrínsecas às diversas ordens ou esferas da vida ganha forma acabada.

Mais do que isso, em Weber encontramos os elementos tanto de afirmação cabal como de crítica radical ao enunciado da autonomização das esferas sociais. Não por acaso, é com base no seu conceito de racionalização formal, e nos seus prognósticos mais sombrios sobre as tendências da modernidade, articulado a uma leitura da teoria do valor em Marx, que Lukács e Adorno/Horkheimer fundamentam os seus respectivos conceitos de reificação e racionalidade instrumental.

A essa tradição que aponta para processos de indiferenciação enraizados não na totalização mítica pré-moderna, mas nas consequências do império da forma valor e da racionalidade instrumental sobre todas as dimensões da vida social, propomos denominar de indiferenciação por identidade (Silva, 2019a).

Neste artigo o interesse é de, após sucinta exposição daqueles enunciados na primeira parte, fundamentar, na segunda parte, a noção de indiferenciação por diferença para denotar uma modulação singular da crítica ao enunciado da autonomização das esferas sociais, presente no conceito de governamentalidade neoliberal e suas afinidades com os conceitos de sociedade de controle e de novo espirito do capitalismo.

Da autonomização das esferas sociais à indiferenciação por identidade

A passagem do uno ao diverso delineia uma característica central tanto na fundação como nos desdobramentos do pensamento ocidental. Dizem ter sido Anaximandro de Mileto o primeiro que "usou a palavra arke" (Bornheim, 1998, p. 24) para designar o princípio de onde tudo procede: para Anaxímenes de Mileto, o ar; para Xenófanes de Cólofon, a terra; para Heráclito de Éfeso, o fogo; para Tales, a água, "porque”, escreve Simplicius sobre Tales, “aquilo que é quente necessita de umidade para viver, e o que é morto seca, e todos os germes são úmidos, e todo alimento é cheio de suco" (Idem, p. 23).

Naturalmente, dos fundamentos da filosofia ocidental nos pré-socráticos, entre os séculos vi e v a.C., ao esforço de, com base em um modelo naturalista, constituir a(s) ciência(s) dos fenômenos sociais, na Europa cristã dos séculos XIX e XX, alteram-se radicalmente as condições históricas, econômicas, sociais, culturais e políticas, e são, decisivamente, homens de um pensamento outro formados por uma nova era. No entanto, não deixa de ser intrigante a perenidade daquele estilo de reflexão sobre a origem e o desenvolvimento das coisas do mundo humano, mas também natural. 
Herbert Spencer (1891, p. 10), em ensaio de 1857, Progress: its law and causes, influenciado por Von Baer, percebe a diferenciação, definida como a passagem do "homogêneo ao heterogêneo" ou do "simples ao complexo", como uma lei universal, válida para todos os domínios da existência, assim como para todo produto do pensamento e ação humanos.

Para o autor inglês, a crescente heterogeneidade e complexidade de todos os domínios do cosmos se deve ao fato nomológico de que "toda força ativa produz mais de uma mudança - toda causa produz mais de um efeito" (Idem, p. 37). Formulação algo tautológica que atribui a diferenciação universal como passagem do homogêneo ao heterogêneo (nos fenômenos inorgânicos, orgânicos, sociais e individuais) à lei de que uma causa (homogeneidade, simplicidade) necessariamente tem mais de um efeito (heterogeneidade, complexidade).

Em fase ulterior de sua carreira, em seus Principles of sociology, Spencer refina a atribuição causal da diferenciação social ao "crescimento de uma população no interior de uma área ecológica delimitada" (Turner, 1984, p. 23). Conceito que terá significativa influência em Durkheim, particularmente em Da divisão do trabalho social, de 1893.

Também num léxico fortemente biológico, Durkheim (2010, p. 2) disserta sobre a crescente autonomia dos "órgãos" e/ou "funções" promovida pela divisão do trabalho social, concebida para além do "mundo econômico" ao exercer "influência crescente nas regiões mais diferentes da sociedade. As funções políticas, administrativas, judiciárias especializam-se cada vez mais. O mesmo ocorre com as funções artísticas e científicas".

Decisiva na constituição de certo discurso sociológico hegemônico sobre a modernidade (Tavolaro, 2007), é a articulação operada por Durkheim entre os conceitos de diferenciação, secularização e individuação ao refletir sobre a passagem do homogêneo ao heterogêneo, do simples ao complexo. Se na pré-modernidade, "tudo que é social é religioso, as duas palavras são sinônimas", na modernidade, "pouco a pouco, as funções políticas, econômicas e científicas se emancipam da função religiosa, constituem-se à parte e adquirem um caráter temporal cada vez mais acentuado". Deus "abandona o mundo aos homens e a suas disputas" e, como consequência, "o indivíduo sente-se, e é realmente menos agido; torna-se muito mais uma fonte de atividade espontânea” (Durkheim, 2010, p. 152).

A mesma importância atribuída à retração do caráter totalizante da religião (secularização) para a diferenciação social é explícita em trecho clássico do Manifesto Comunista de 1848, quando Marx e Engels discutem as implicações da expansão e estabelecimento da sociedade burguesa que: 
Afogou os fervores sagrados da exaltação religiosa, do entusiasmo cavalheiresco, do sentimentalismo pequeno-burguês nas águas geladas do cálculo egoística [...] em lugar da exploração dissimulada por ilusões religiosas e políticas [...] colocou uma exploração aberta, direta, despudorada e brutal [...] tudo o que era sagrado é profanado e os homens são obrigados finalmente a encarar sem ilusões a sua posição social e as suas relações com os outros homens (1998, p. 51).

É, no entanto, no contexto alemão, nos marcos de uma tentativa pós-kantiana de fundamentação da especificidade das ciências humanas ou do espírito (posteriormente denominadas históricas e culturais), movimento que vai de Wilhelm Dilthey à filosofia neokantiana dos valores, portanto enfaticamente distinto do esforço naturalista de Spencer e Durkheim, que o conceito de diferenciação social será modulado como um movimento de autonomização crescente das esferas sociais.

Em Dilthey, é a unicidade da vivência - "como algo especificamente social (pela sua dimensão intersubjetiva) e cultural (pela sua dimensão significativa)" (Cohn, 2003, p. 26) - que se diversifica em expressões ou, rigorosamente, "sistemas de fins" (Dilthey, 2010, p. 26) múltiplos e específicos tais como arte, filosofia, religião, ciência, direito e geram, como esforços de compreensão, também variadas disciplinas.

Simmel pensa a relação entre formas e vida de forma análoga à relação entre expressões e vivência em Dilthey. É dos conteúdos ou "das matérias com as quais a vida se preenche" - a "fome, o amor, o trabalho, a religiosidade, a técnica, as funções ou resultados da inteligência”, que "não são, em seu sentido imediato, por si sós, sociais" (Simmel, 2006, p. 60) - que emergem as formas sociais, quando as "forças" e "interesses", em suma, os conteúdos, "se liberam, de um modo peculiar, do serviço à vida que os havia gerado e aos quais estavam originalmente presos", e tornam-se "autônomos, no sentido de que não se podem mais separar do objeto que formaram exclusivamente para seu próprio funcionamento e realização" (Idem, p. 61). Exemplifica (Idem, pp. 61-64) a autonomização das formas em relação aos conteúdos vitais através da ciência, da arte, do direito, do jogo, da sociabilidade.

Tanto na hermenêutica diltheyana, que supõe a vivência como origem das expressões e da compreensão, como no vitalismo simmeliano, que vai do fluxo da vida às formas, resta um acentuado caráter especulativo, senão metafísico, na apreciação dos processos de diferenciação/autonomização das esferas sociais. Max Weber, entre os alemães, retorna a um marco mais propriamente sociológico para pensar o mesmo processo. Como Durkheim, Weber também concebe a pré-modernidade como caracterizada pela totalização religiosa, mais especificamente, pela totalização mágica já que é num desdobramento interno à história das religiões, quando estas se tornam religiões proféticas de salvação, que se abrem as condições para o ocaso da unidade mágica do mundo. 
É principalmente na já clássica Consideração intermediária, entre o estudo das religiôes chinesas e indianas nos Ensaios comparados de sociologia das religióes, que se concentra a imagem weberiana da passagem da pré-modernidade à modernidade (Sell, 2013).

Em contraste com a magia, na qual o carisma é exercido para fins circunstanciais e imediatos visados por uma clientela formada por indivíduos, as religiões de salvação tendem a racionalizar, com base na mensagem profética, a conduta de vida como um todo dos fiéis, visando "bens salvíficos interiores, concebidos como meio de redenção" (Weber, 2016, p. 368). Tal desenvolvimento desencadeia uma necessidade crescente de "racionalização" e "sublimação conscientes das relações dos humanos com as diferentes esferas de posse de bens, interiores e exteriores, religiosos e mundanos", exigência que levou "a que as legalidades próprias [Eigengesetzlichkeiten] das diferentes esferas se tornassem conscientes quanto à sua coerência interna, e isso fez com que se acirrassem aquelas tensões recíprocas que haviam permanecido ignoradas enquanto reinou a ingenuidade primitiva na relação com o mundo exterior" (Idem, p. 368).

Weber (Idem, pp. 369-398) trata dos compromissos e das tensões entre as seguintes esferas da vida social: religiosa (ética da fraternidade), econômica (lucro privado por meio do empreendimento), política (monopólio do uso ou ameaça legítima da violência), estética (a forma como promessa de salvação intramundana), erótica (o erotismo valorizado em si mesmo, também como promessa de salvação intramundana), intelectual (primado da investigação empírica de relações causais contra toda forma de causalidade ética).

Particularmente significativa, em seus efeitos ulteriores na teoria sociológica, é a tensão, constitutiva da modernidade ocidental, entre a expansão exacerbada das ordens de racionalização formal (econômica, política, intelectual), que se orientam pela possibilidade de cálculo, e as esferas (erótica e estética) que buscam uma redenção intramundana, como fuga "das frias mãos esqueléticas" (Idem, 391) do mercado, da burocracia e da ciência, que também atrofiam o espaço para o desenvolvimento de uma ética da fraternidade universal. Prognóstico que já havia sido antecipado nas páginas finais de $A$ ética protestante o espirito do capitalismo, quando Weber (2004, p. 165) aponta as tendências de generalização do racionalismo econômico como "estilo de vida" típico da modernidade e de conversão do "cuidado com os bens exteriores" de "leve manto de que se pudesse despir a qualquer momento" (Richard Baxter) em uma "rija crosta de aço".

Vê-se assim como, para Weber, por um lado, é da crise da unificação mágica do mundo que emerge a diversificação e autonomização em legalidades próprias das diversas esferas ou ordens sociais; por outro, assinala-se a tendência a uma hipertrofia da racionalização formal-instrumental em relação a outras dimensões da vida. 
Pode-se dizer que duas linhagens emergem na teoria sociológica com base nas análises e prognósticos da sociologia weberiana do racionalismo: a da diferenciação funcional e a da reificação.

A linhagem da diferenciação funcional como característica fundamental da sociedade moderna enfatiza radicalmente os aspectos de autonomização e autoencerramento das funções (Durkheim) ou esferas (Weber) sociais.

Num tom deveras clássico, Parsons $(1969,1974)$ concebe a transição do pré-moderno ao moderno em termos da separação entre sociedade e religião e, como consequência, da diferenciação entre os respectivos subsistemas funcionais e seus meios simbólicos generalizados: no subsistema cultural, a influência; no subsistema de governo, o poder; no subsistema econômico, o dinheiro; no subsistema social, a lealdade.

Em Luhmann (1998, 2006, 2010), por sua vez, o próprio conceito de sociedade moderna é definido pelo primado da diferenciação funcional, ou seja, pela supressão evolucionária do primado étnico ou de moradia (diferenciação segmentária) e pelo primado estamental (diferenciação por estratificação) em nome do desenvolvimento equivalente (cada um é tão importante quanto o outro para a integração do sistema social mais amplo) e desigual (cada sistema funcional tem uma função exclusiva e intransitiva) dos sistemas funcionais, encerrados operativamente através de códigos binários: imanência/transcendência na religião; arte/não-arte; pagamento/ não-pagamento na economia; verdade/falsidade na ciência; governo/oposição na política; licitude/ilicitude no sistema jurídico etc.

Se Parsons fala em estruturas emergentes da interpenetração entre os subsistemas e Luhmann dos acoplamentos estruturais entre os sistemas funcionais, é crucial para ambos a preservação da autonomia das funções em nome do equilíbrio (instável em Luhmann) do sistema social ${ }^{2}$.

A linhagem da reificação, influenciada mais ou menos amplamente pela crítica marxiana da sociedade burguesa, enfatiza os limites para a autonomização das

2. Luhmann nos aproxima de uma concepção absoluta da autonomia dos sistemas funcionais, já que os acoplamentos estruturais de modo algum negam a autopoiesis dos sistemas funcionais (a negação da autopoiesis é sempre a destruição do sistema), enquanto Bourdieu (2007, 2008, 2009, 2010), busca formular de maneira rigorosa o caráter relativo da autonomia dos campos. Pode-se dizer que a noção de campo procura dar a devida importância às duas faces daquela ambivalência dos diagnósticos weberianos sobre a modernidade: a reprodução das hierarquias rígidas do campo de poder e do espaço social mais amplo ganha em eficácia e perenidade através do desenvolvimento de um léxico e de práticas de autonomia. $\mathrm{O}$ conceito de habitus também é central para tornar inteligível a forma como posições desiguais no espaço social são traduzidas em posições desiguais no interior dos campos, na medida em que é por meio dos habitus que os códigos sociais mais amplos de igualdade/desigualdade são reproduzidos, de forma complexa, nos códigos de distinção exclusivos aos campos em particular. Por isso a impossibilidade de falar em campos como sistemas ou em termos de primazia funcional (no sentido luhmanniano), já que a autonomização dos campos é sempre uma forma de reprodução do espaço social. 
esferas em relações estruturadas pela forma valor ou orientadas pela racionalidade instrumental.

Num contexto histórico de ainda maior aprofundamento da subordinação da produção a princípios de calculabilidade e previsibilidade sob os ditames da taylorização, Lukács (2003) realiza uma articulação da teoria weberiana da racionalização e da teoria marxiana do fetichismo da mercadoria.

No conceito de reificação nos importa salientar principalmente o seu caráter paradoxal, admitido por Lukács (2003): por um lado, a subordinação de todas as esferas da vida a uma mesma estrutura de racionalização formal (previsibilidade, calculabilidade, quantificação), conformadora de estruturas homólogas de subjetividade (imediatismo, factualidade), é vista como uma lei geral das sociedades capitalistas; por outro, Lukács (Idem, pp. 227-228) não percebe como mera ilusão o processo de autonomização das esferas em particular, reconhecendo assim a efetividade de dinâmicas reais de legalidade própria no interior das ordens da vida social. A reifcação integra, portanto, a totalidade não através da homogeneização das partes, mas através da imposição a estas de uma mesma lógica de racionalização formal, não necessariamente conteudística.

Feridos pelos desenvolvimentos bárbaros do capitalismo monopolista, a expansão da maquinaria simbólica da indústria cultural, a ascensão e queda de regimes fascistas e a burocratização da revolução soviética em seu momento termidoriano, é no desenvolvimento da problemática da reificação em Adorno e Horkheimer (1985), já que eles trilham o mesmo caminho de síntese entre racionalização e teoria do valor, que se realiza a dissolução daquele paradoxo preservado na consciência do tempo de Lukács.

Para os primeiros, a imposição de uma mesma lógica de racionalização formal a todas as esferas da sociedade dá-se acompanhada de uma homogeneização dos próprios conteúdos. A harmonia bárbara entre as partes e o todo anuncia a reificação como generalização de uma lógica da identidade. Assim, a autonomia das esferas aparece como ilusória perante a integração totalitária de toda a sociedade por uma cultura de massas brutal e replicadora da lógica do trabalho industrial, o que configura uma indiferenciação por identidade, antípoda do enunciado da autonomização das esferas sociais $s^{4}$.

3. "A separação do produtor dos seus meios de produção, a dissolução e a desagregação de todas as unidades originais de produção etc., todas as condições econômicas e sociais do nascimento do capitalismo moderno agem nesse sentido: substituir por relações racionalmente reificadas as relações originais em que eram mais transparentes as relações humanas. [...] o princípio da mecanização racional e da calculabilidade deve abarcar todos os aspectos da vida (Lukács, 2003, p. 207).

4. A teoria habermasiana do agir comunicativo (Habermas, 2012a, 2012b) também pode ser pensada 
Indiferenciação por diferença

Na literatura crítica (Honneth, 1994; McCarthy, 1994) que sucede o trabalho de Habermas (2000), é perceptível uma tendência a evidenciar as afinidades da genealogia foucauldiana principalmente com a primeira geração da Escola de Frankfurt, demarcando a diferença em relação à teoria dualista da racionalização habermasiana e a defesa normativa da continuação do projeto de modernidade como descolonização do mundo da vida. No entanto, por ser dos anos 1980 e 1990, tal literatura se limita à crítica da análise das formas disciplinares de tecnologia política, dando reduzida atenção aos conceitos de biopolítica e nenhuma atenção ao conceito de governamentalidade, já que os cursos do Collège de France dedicados ao tema só foram integralmente publicados nos anos 2000.

Adorno, Horkheimer e Foucault ${ }^{5}$ se uniriam, segundo Honneth (1994, pp. 178181): (a) em um tipo de "investigação histórica" que percebe a "história europeia" como um "processo de racionalização no qual os meios de dominação são gradualmente aperfeiçoados sob o véu da emancipação mental"; (b) ao assumirem "que a realização prática da dominação foi metodologicamente controlada e otimizada reflexivamente pelo desenvolvimento das ciências humanas e naturais"; (c) como consequência, os três autores veem "o processo de racionalização técnica culminar nas organizações de dominação 'totalitárias' das sociedades altamente desenvolvidas". No entanto, enquanto para Adorno e Horkheimer tal resultado é "produzido pelo planejamento e pelas atividades manipulativas de uma administração centralizada", para Foucault, "as realizações necessárias garantidas pelos procedimentos disciplinares e de controle são produzidas por organizações unidas institucionalmente, como a escola, a prisão e a fábrica”.

como mais um esforço, como salientamos em relação a Bourdieu, de resolver as ambivalências internas à teoria da racionalização weberiana. Caudatário direto daquela teoria crítica (Adorno e Horkheimer) que leva às últimas consequências a relação entre racionalização e dominação (delineando o que chamamos de indiferenciação por identidade), Habermas não nega tal entrelaçamento no que se refere à racionalização constitutiva das esferas econômica (mercado) e política (Estado) nas sociedades modernas, orientadas por uma racionalidade cognitivo-instrumental. O problema, para Habermas, é reduzir a racionalização moderna à racionalidade formal cognitivo-instrumental e não seguir a linha aberta de investigação e teorização, presente inclusive na sociologia da religião de Max Weber, sobre formas pós-tradicionais de racionalização material moral-prática. Assim, por um lado, Habermas endossa elementos de indiferenciação por identidade, formulada como colonização sistêmica do mundo da vida, para explicar o espraiamento do agir orientado para o êxito e da racionalidade cognitivo-instrumental para esferas heterogêneas (em relação àquele agir e àquela racionalidade) da vida social. Por outro lado, retorna à tese da raciononalização/autonomização para demonstrar as possibilidades abertas de racionalização para além da crosta de aço.

5. Um esforço de reflexão mais esquemático sobre as convergências e divergências entre a genealogia foucauldiana e a escola de Frankfurt poder ser encontrado em McCarthy (1994). 
Assim, teríamos, segundo Honneth, na sociedade administrada (primeira geração de Frankfurt) e na sociedade disciplinar (Vigiar e Punir) dois diagnósticos sobre a integração total, sobre o caráter totalitário das sociedades modernas. Embora o primeiro diagnóstico seja caudatário da ideia de reificação e assim impute tal totalização, em última instância, ao valor como abstração real e à generalização (da produção ao lazer, da fábrica à cultura) da racionalidade instrumental, enquanto o segundo privilegia o desenvolvimento de múltiplas tecnologias disciplinares pós-soberanas ${ }^{6}$, ambos convergem numa imagem monocromática e homogeneizante da Europa e dos Estados Unidos pós II Guerra, em que tudo, parafraseando Adorno e Horkheimer (1985), tem um ar de identidade e semelhança.

Numa entrevista de 1973 com A. Krywin e F. Ringelheim - ou seja, antes da publicação de Surveiller et punir (1975) e no contexto das suas atividades no GIP -, Foucault endossa tal conclusão que o aproxima do diagnóstico sobre a total integração/ identidade realizado pelo processo de racionalização formal das sociedades modernas. Em certo momento, ao ser perguntado sobre a especificidade da "relação [...] entre as diversas formas de internamento", da "analogia entre a escola, a caserna, a usina, a prisão", caso "trata-se de semelhanças fortuitas ou exteriores, ou então ao contrário, de uma analogia de natureza", Foucault não hesita:

Penso que seja, no fundo, a estrutura do poder própria a essas instituições que é exatamente a mesma. E, na verdade, não se pode dizer que há analogia, há identidade. É o mesmo tipo de poder, é o mesmo poder que se exerce. E está claro que esse poder que obedece à mesma estratégia não pretende, finalmente, o mesmo objetivo. Ele não serve às mesmas finalidades econômicas, quando se trata de fabricar alunos, quando se trata de 'fazer' um delinquente, quer dizer, quando se trata de constituir esta personagem definitivamente inassimilável na qual se torna o tipo ao sair da prisão. Quando o senhor fala de analogia de natureza entre essas instituições, eu não assinaria embaixo disso inteiramente. Eu diria identidade morfológica do sistema de poder. (2010, pp. 74-75)

Temos aqui um Foucault (ao afirmar que a "estrutura do poder [...] é exatamente a mesma" em instituições aparentemente tão distintas ou ao negar a "analogia" quando o que de fato existe é uma "identidade morfológica do sistema de poder") fortemente afim ao diagnóstico da reificação total ou do que chamamos de indife-

6. “A 'invenção' dessa nova anatomia política não deve ser entendida como uma descoberta súbita. Mas como uma multiplicidade de processos muitas vezes mínimos, de origens diferentes, de localizações esparsas, que se recordam, se repetem, ou se imitam, apoiam-se uns sobre os outros, distinguem-se segundo seu campo de aplicação, entram em convergência e esboçam aos poucos a fachada de um método geral" (Foucault, 1987, p. 119). 
renciação por identidade presente em Adorno e Horkheimer (embora negue certa primazia do econômico em favor de uma história transversal e totalizante das relaçóes de poder).

Entretanto, uma ampliação do material, incluindo os cursos no Collège de France que apresentam as etapas de formação conceitual da governamentalidade, possibilita construir uma imagem mais nuançada e complexa do pensamento de Foucault e de como a sua genealogia da governamentalidade neoliberal, em particular, aponta para uma forma de indiferenciação que se realiza não por identidade, mas por diferença.

Entre 1974 e 1976, Foucault já exprime, através da análise de objetos específicos (como a medicina social, o racismo, a sexualidade), o interesse em investigar a formação de uma racionalidade política orientada para a regulamentação da população. Em A vontade de saber, de 1976, o biopoder é definido pela articulação entre anátomo-política (corpos individuais) e biopolítica (corpo da população). Em Segurança, território, população (curso de 1977-1978), numa significativa inflexão em relação tanto a Vigiar e punir como em relação a $A$ vontade de saber (Silva, 2019b), a anátomo-política é pensada como uma tecnologia política arcaica e o "panóptico", alegoria maior do poder disciplinar, como "o mais antigo sonho do mais antigo soberano: que nenhum dos meus súditos escape e que nenhum dos gestos de nenhum dos meus súditos seja desconhecido" (Foucault, 2008a, p. 87).

Daí em diante, a modernidade do poder será definida, para Foucault, não mais pela sociedade disciplinar, mas pela governamentalidade, essa racionalidade de governo que tem como objeto a população. Aquela rede de instituições disciplinares restritivas, voltadas para a produção de corpos dóceis através do confinamento, da delimitação e da vigilância, e que exprimiam a "identidade morfológica do sistema de poder", torna-se, nas palavras de Deleuze (1992, p. 220), o "que já não éramos mais", o "que deixávamos de ser" diante da emergência de um poder centrífugo, expansivo, onipresente e produtivo que exerce "regulação no elemento da realidade" (Foucault, 2008a, p. 61). Ao abandonar o conceito de sociedade disciplinar, o pensamento de Foucault também se distancia daquelas afinidades assinaladas com os conceitos de sociedade administrada ou unidimensional.

A governamentalidade, "que é ao mesmo tempo exterior e interior ao Estado", é definida por Foucault (2008a, p. 143) como o "o conjunto constituído pelas instituições, os procedimentos, análises e reflexões, os cálculos e as táticas que permitem exercer essa forma [...] de poder que tem por alvo principal a população, por principal forma de saber a economia política e por instrumento técnico essencial os dispositivos de segurança"; o conjunto de "táticas de governo que, a cada instante, permitem definir o que deve ser do âmbito do Estado e o que não deve, o que é público e o que é privado, o que é estatal e não estatal", de modo que "o Estado em sua sobrevivência 
e o Estado em seus limites só devem ser compreendidos a partir das táticas gerais de governamentalidade" (Idem, p. 145).

Elaborada nos discursos e práticas dos fisiocratas e da economia política, a governamentalidade liberal se caracteriza, em termos gerais, pela produção de um regime de verdade sobre a economia como domínio natural próprio e autônomo, cuja dinâmica de interesses tenderia a realizar o equilíbrio das necessidades populacionais. Consequência fundamental dessa verdade produzida é a constituição da governamentalidade liberal como um "princípio de autolimitação do governo" (Idem, p. 26 e também p. 336), que traça uma linha demarcatória entre o domínio do econômico, em que não deve haver intervenção estatal (ou unicamente para preservar a autonomia do mercado), e um domínio do político (relação entre Estado e sociedade civil).

A governamentalidade neoliberal, por sua vez, é especificada pela defesa intransigente do mecanismo de concorrência após as experiências comunista, fascista e keynesiana de crítica prático-discursiva ao liberalismo clássico. Para os ordoliberais e neoliberais analisados por Foucault, não se trata mais de uma defesa, como no velho liberalismo, dos limites que separam o econômico, na qualidade de uma natureza autônoma e autorregulada, de um lado, e o político-estatal, de outro, mas de "uma formalização geral dos poderes do Estado e da organização da sociedade a partir de uma economia de mercado" (Foucault, 2008b, p. 160).

Enquanto o liberalismo clássico concebe o mercado como tendo uma dinâmica intrínseca, natural, tendente à satisfação das necessidades da população, e é por isso que o Estado não deve intervir no seu domínio ou no máximo vigiar para manter o seu equilíbrio, o neoliberalismo defende que a essência (a concorrência) da economia de mercado não se realiza de forma espontânea, mas apenas sob certas condições políticas, jurídicas e institucionais que devem ser induzidas ou construídas por ação humana e não natural. É por isso que ordoliberais como Röpke, Eucken, mas também Rougier e Hayek defendem um tipo de ativismo politico sem dirigismo não só distinto, mas antagônico a concepções intervencionistas (de tipo keyneasiano) ou planificadoras (de tipo comunista), tendentes sempre, no interior do discurso ordo e neoliberal, ao totalitarismo (Idem, p. 157).

De um ponto de vista jurídico, tal ativismo se define pela reorientação radical do direito "em função da economia concorrencial de mercado" (Idem, p. 222): eliminando as distorções jurídico-institucionais intervencionistas, desfuncionalizando ou atrofiando o braço administrativo dirigista do Estado e fornecendo as regras do jogo concorrencial através da multiplicação das instâncias judiciárias nas quais os jogadores (agentes da concorrência) poderão reclamar do possível desrespeito à moldura formal do jogo mercantil (Idem, pp. 222-242). 
De um ponto de vista mais abrangente e profundo, os ordoliberais defendem a constituição "não de um governo econômico, como aquele que sonhavam os fisiocratas", mas de "um governo da sociedade" (Idem, p. 199), de uma Gesellschaftspolitik que se exerça sobre "o ambiente social" (Foucault, 2008b, p. 200). Busca-se "fazer do mercado, da concorrência e, por conseguinte, da empresa o que poderíamos chamar de poder enformador da sociedade" (Idem, p. 203), orientado para a constituição de "uma sociedade indexada, não na mercadoria e na uniformidade da mercadoria, mas na multiplicidade e na diferenciação das empresas" (Idem, p. 228).

O modelo neoliberal estadunidense, na acepção de Foucault, leva ao paroxismo a imagem de um poder enformador da sociedade que objetiva ler e indexar todos os domínios da vida e da ação sociais em termos do modelo empresarial. Gary Becker é exemplar ao considerar todo indivíduo como "um empresário, um empresário de si mesmo", "sendo ele próprio seu capital, sendo para si mesmo seu produtor, sendo para si mesmo a fonte de [sua] renda” (Idem, p. 311). Tal enquadramento dos sujeitos como empresários de si, capital humano, que concebe o próprio consumo como uma reprodução ampliada, é generalizado, por Becker, para pensar a genética, o matrimônio, a procriação (visando otimizar o capital por meio dos descendentes), a saúde, a higiene pública, as migrações (Idem, pp. 314-315), mas também a criminalidade e a delinquência (Idem, pp. 339-353).

É, portanto, também, uma nova concepção de homo oeconomicus que surge com os discursos e práticas neoliberais. No liberalismo clássico, o homo oeconomicus é um parceiro individual da troca, em que a utilidade perseguida por sua ação visa satisfazer certas necessidades; no neoliberalismo, por sua vez, o bomo oeconomicus é uma empresa, um capital humano, que age sempre no sentido de valorizar a si mesmo como capital.

Dardot e Laval (2016, p. 7), amparados no instrumental analítico da governamentalidade, podem assim afirmar que "o neoliberalismo não é apenas uma ideologia", nem "um tipo de política econômica", mas "um sistema normativo que ampliou sua influência no mundo inteiro, estendendo a lógica do capital a todas as relações sociais e a todas as esferas da vida". Entendido como "racionalidade", o neoliberalismo "tende a estruturar e organizar não apenas a ação dos governantes, mas até a própria conduta dos governados", tendo como "característica principal a generalização da concorrência como norma de conduta e da empresa como modelo de subjetivação" (Idem, p. 17).

Mas, afinal, isso não seria apenas a reformulação da preponderância do econômico numa análise do capitalismo liberal e neoliberal?

A resposta é negativa por pelo menos três razões: (a) em primeiro lugar, porque o nominalismo foucauldiano em geral (da arqueologia à genealogia), nesse caso semelhante a Weber, rejeita um juízo ontológico sobre o primado de qualquer instância 
da sociedade tomada como real; (b) em segundo lugar, pela forma como Foucault concebe as práticas (discursivas e não discursivas), os discursos liberal e neoliberal não podem ser pensados como reflexo de fases específicas do capitalismo - tais discursos, que emergem em condições históricas particulares, também constituem as práticas econômicas, políticas, jurídicas etc. ${ }^{7}$, são tanto efeito como causa; (c) por último, porque as práticas são pensadas através de uma determinada compreensão de governamentalidade, ou seja, de uma racionalidade de governo que é mais abrangente do que o Estado e também não pode ser reduzida a uma expressão ideológica emergente de posições específicas na estrutura de classes ou nas relações de produção.

Da mesma forma como não é resultado direto de uma doutrina homogênea, a sociedade neoliberal não é reflexo de uma lógica do capital que suscita as formas sociais, culturais e políticas que lhe convém à medida que se expande. [...] [A] originalidade do neoliberalismo está no fato de criar um novo conjunto de regras que definem não apenas outro "regime de acumulação", mas também, mais amplamente, outra sociedade. Tocamos aqui num ponto fundamental. Na concepção marxista, o capitalismo é, antes de tudo, um 'modo de produção' econômico que, como tal, é independente do direito e gera a ordem jurídico-política de que necessita a cada estágio de seu autodesenvolvimento. Ora, longe de pertencer a uma 'superestrutura' condenada a exprimir ou obstruir o econômico, o jurídico pertence de imediato às relações de produção, na medida em que molda o econômico a partir de dentro (Idem, pp. 24-25).

É inegável, porém, a afinidade da análise foucauldiana do capital humano com uma noção de racionalidade instrumental que, sob a aparente autonomia da ação racional teleologicamente orientada, submete-se inteiramente ao ambiente e a fins socialmente impostos. No entanto, diferente de um juízo sobre a reificação ou integração totais (que pode ser extraído de Vigiar e punir), Foucault (2008b), por um lado, realiza uma análise de discursos historicamente específicos, sobre os quais ele afirma perceber a progressiva realização nas ou apropriação pelas políticas governamentais de países desenvolvidos no seu tempo. Diagnóstico de tendências prático-discursivas de um presente situado, portanto, e não diagnóstico absolutizante sobre a barbárie inescapável do capitalismo tardio.

7. "A criação de um Estado de direito (Rechtstaat) é a condição dessa ordem liberal. Isso significa que o estabelecimento e o funcionamento do capitalismo não são predeterminados: eles dependem das ações políticas e das instituições jurídicas. Michel Foucault insiste com toda razão na importância de confrontar essa concepção com a concepção marxista da história do capitalismo dominante na época. De fato, o ordoliberalismo rejeita com vigor toda forma de redução do jurídico a uma simples 'superestrutura,' assim como a ideia correlativa da economia como infraestrutura”' (Dardot e Laval, 2016, p. 103). 
Por outro lado, também contrastivamente, Foucault realiza uma análise de uma indiferenciação situada no interior de um programa genealógico mais amplo dos regimes de veridição, dessa vez tomando a governamentalidade como objeto, e não a análise do processo único e irreversível de identificação entre racionalidade e dominação.

Ao que nos parece, a especificidade de Foucault e sua análise da biopolítica no interior das críticas ao enunciado da autonomização das esferas em sociedades modernas (incluindo a sua própria imagem da sociedade carcerária em Vigiar e punir), está precisamente neste caráter situado, na historicidade de suas análises sobre a interpenetração ou indiferenciação de códigos tomados, numa perspectiva funcionalista, como distintos. Não se trata, como a crítica frankfurtiana, de estabelecer um corte entre a pré-modernidade e a modernidade capitalista e afirmar: antes a indiferenciação totalizante operada pela religião, agora a indiferenciação enraizada na abstração real da forma-valor, no estranhamento ou na dominação/colonização $\mathrm{da}$ racionalidade instrumental.

Diferente de uma indiferenciação por identidade, como denominamos a reificação total operada pela racionalidade instrumental no pensamento de Adorno e Horkheimer, podemos chamar a indiferenciação situada elaborada na análise foucauldiana do complexo prático-discursivo neoliberal, de uma indiferenciação por diferença. É o próprio tex to de Nascimento da Biopolítica que nos oferece elementos para tal formulação, quando em contenda com uma crítica da mercantilização radical, do espetáculo e da unidimensionalidade no capitalismo tardio, Foucault (Idem, p. 204) enfatiza que o objetivo da governamentalidade neoliberal não é a identidade e a massificação, mas, pelo contrário, a "multiplicidade" e a "diferenciação das empresas". Em outras palavras, não se trata de homogeneizar o diverso, mas de promover a diferenciação valendo-se de uma mesma estrutura objetiva - a economia de mercado - e subjetiva - o capital humano.

O neoliberalismo, em contraste com a identidade liberal, promove, efetiva e se legitima através de um discurso da diferença. A orientação de todas as esferas para a constituição do mercado e a redução de todas as racionalidades à racionalidade utilitária funciona como um terreno uniformizado para a pluralização das unidades-empresa.

É essa mesma passagem da identidade para a diferença que Deleuze (1992, p. 221) aponta como transição da fábrica para a empresa, da disciplina para o controle, dos moldes para as modulações, da constituição dos "indivíduos em um só corpo" para a "rivalidade inexpiável" de cada um para com cada um.

\footnotetext{
Na sociedade disciplinar, portanto, a relação entre o poder e o indivíduo permaneceu estável: a invasão disciplinar de poder correspondeu à resistência do indivíduo. Em contraste com isso, quando o poder se torna inteiramente biopolítico, todo o corpo social é abarcado pela máquina de poder e desenvolvido em suas virtualidades. Essa relação é aberta, qualitativa
} 
e expressiva. [...] O poder é, dessa forma, expresso como um controle que se estende pelas profundezas da consciência e dos corpos da população - e ao mesmo tempo através da totalidade das relações sociais (Hardt e Negri, 2001, pp. 43-44).

Para Hardt e Negri (Idem, p. 44), "em vez de concentrar-se na unidimensionalidade do processo descrito por Marx e reformulado e ampliado pela Escola de Frankfurt, a transição foucauldiana lida fundamentalmente com o paradoxo da pluralidade e da multiplicidade". O "paradoxo de um poder que, à medida que unifica e envolve todos os elementos da vida social (perdendo com isso sua capacidade efetiva de mediar diferentes forças sociais), nesse exato momento revela um novo contexto, um novo milieu de máxima pluralidade e incontornável singularização - um milieu do evento”.

A mesma intelecção de uma transição, de uma passagem, no interior da história do capitalismo, de uma lógica da identidade (das causas e dos efeitos, da produção e do consumo, do trabalho e do tempo livre, do tangível e do intangível, da matéria e da cultura) para uma lógica da diferença (operada por uma indiferenciação de base das instâncias e das racionalidades) é percebida por Boltanski e Chiapello quando percebem a constituição de um novo espirito do capitalismo que busca incorporar a crítica estética da alienação e das disciplinas, tendo como marco histórico o maio de 68 e a contracultura dos anos 1970, e enfatiza crescentemente, noções de

[...] autonomia, espontaneidade, mobilidade, capacidade rizomática, polivalência (em oposição à especialização estrita da antiga divisão do trabalho), comunicabilidade, abertura para os outros e para as novidades, disponibilidade, criatividade, intuição visionária, sensibilidade para as diferenças, capacidade de dar atenção à vivência alheia, aceitação de múltiplas experiências, atração pelo informal e busca de contratos interpessoais (Boltanski e Chiapello, 2009, p. 130).

Desvincula-se assim, continuam Boltanski e Chiapello (Idem, ibidem), a "crítica à divisão do trabalho, à hierarquia e à supervisão, ou seja, ao modo como o capitalismo industrial aliena a liberdade", de uma "crítica à alienação mercantil" e "à opressão pelas forças impessoais do mercado". Tanto Foucault - ao analisar o complexo prático-discursivo ordo e neoliberal - como Boltanski e Chiapello - ao analisarem "a literatura da gestão empresarial destinada a executivos" (Idem, p. 83) - atentam para o paradoxo de uma defesa simultânea da liberdade e da diferença, de um lado, e da inquestionabilidade e ampliação totalizante da economia de mercado, do outro.

A indiferenciação por diferença do discurso neoliberal, podemos afirmar conclusivamente e no espírito de uma sociologia da crítica, distingue-se da indiferenciação por identidade por também buscar se afirmar como crítica da reificação. 


\section{Referências Bibliográficas}

Adorno, T \& Horkheimer, M. (1985), Dialética do esclarecimento. Rio de Janeiro, Jorge Zahar.

Boltanski, L. \& Chiapello, E. (2009), O novo espírito do capitalismo. São Paulo, Martins Fontes.

Bourdieu, Pierre. (2007), A economia das trocas simbólicas. São Paulo, Perspectiva.

Bourdieu, Pierre. (2008), A distinção: crítica social do julgamento. São Paulo/Porto Alegre, Edusp/Zouk.

Bourdieu, Pierre. (2009), Senso prático. Petrópolis, Vozes.

Bourdieu, Pierre. (2010), O poder simbólico. Rio de Janeiro, Bertrand Brasil.

Bornheim, Gerd A. (1998), Os filósofos pré-socráticos. São Paulo, Editora Cultrix.

CoHn, Gabriel. (2003), Crítica e resignação: Max Weber e a teoria social. São Paulo, Martins Fontes.

Dardot, Pierre \& Laval, Christian. (2016), A nova razão do mundo. São Paulo, Boitempo.

Deleuze, Gilles. (1992), “Post-scriptum sobre as sociedades de controle”. In: Deleuze, Gilles. Conversações, 1972-1990. São Paulo, Editora 34.

Dilthey, Wilhelm. (2010), A construção do mundo histórico nas ciências humanas. São Paulo, Editora Unesp.

Durkheim, Émile. (2010), Da divisão do trabalho social. São Paulo, Martins Fontes.

Foucault, Michel. (1979), "O nascimento da medicina social": In: Machado, Roberto (org.). Microfísica do poder. Rio de Janeiro, Edições Graal.

Foucault, Michel. (1987), Vigiar e punir. Petrópolis, Vozes.

Foucault, Michel. (1988), História da sexualidade. Vol.1: A vontade de saber. Rio de Janeiro, Edições Graal.

Foucault, Michel. (1994), "Critical theory/Intellectual history”. In: Kelly, Michael (ed.). Critique and power: recasting the Foucault/Habermas debate. Massachusetts, The MIT Press.

Foucault, Michel. (1999), Em defesa da sociedade. São Paulo, Martins Fontes.

Foucault, Michel. (2008a), Segurança, território, população. São Paulo, Martins Fontes.

Foucault, Michel. (2008b), Nascimento da biopolitica. São Paulo, Martins Fontes.

Foucault, Michel. (2010), Ditos e Escritos. Vol. 4: Estratégia, poder-saber. Organização e seleção de textos: Manoel Barros da Motta. Rio de Janeiro, Forense Universitária.

Habermas, Jürgen. (2000), O discurso filosófico da modernidade. São Paulo, Martins Fontes.

Habermas, Jürgen. (2012a), Teoria do agir comunicativo. Vol. 1: Racionalidade da ação e racionalização social. São Paulo, wMF Martins Fontes.

Habermas, Jürgen. (2012b), Teoria do agir comunicativo. Vol. 2: Sobre a critica da razão funcionalista. São Paulo, wMF Martins Fontes. 
Hardt, Michael \& Negri, Antonio. (2001), Império. Rio de Janeiro, Record.

Honneth, Axel. (1994), "Foucault's theory of society: a systems-theoretic dissolution of the Dialectic of enlightenment". In: Kelly, Michael (ed.). Critique and Power: recasting the Foucault/Habermas debate. Massachusetts, The MIT Press.

Luhmann, Niklas. (1998), Complejidad y modernidad: de la unidad a la diferencia. Madrid, Trolla. Luhmann, Niklas. (2006), La sociedad de la sociedad. México, Herder.

Luhmann, Niklas. (2010), Introdução à teoria dos sistemas. Petrópolis, Vozes.

LukÁcs, Georg. (2003), História e consciência de classe. São Paulo, Martins Fontes.

Marx, Karl \& Engels, Friedrich. (1998), O Manifesto do Partido Comunista. São Paulo, Boitempo.

McCarhty, Thomas. (1994), "The critique of impure reason: Foucault and the Frankfurt School". In: Kelly, Michael (ed.). Critique and power: recasting the Foucault/Habermas debate. Massachusetts, The MIT Press.

Parsons, Talcott. (1969), Sociedades: perspectivas evolutivas e comparativas. São Paulo, Enio Matheus Guazzelli \& Cia.

Parsons, Talcott. (1974), O sistema das sociedades modernas. São Paulo, Pioneira.

SEll, Carlos Eduardo. (2013), Max Weber e a racionalização da vida. Petrópolis, Vozes.

Silva, Lucas Trindade da. (2018), Biopolítica e o enunciado da autonomização das esferas sociais. Brasília, tese de doutorado em sociologia, Universidade de Brasília.

Silva, Lucas Trindade da. (2019a), "Indiferenciação por identidade: de história e consciência de classe à dialética do esclarecimento". Revista Brasileira de Sociologia, 15 (7): 255-283.

Silva, Lucas Trindade da. (2019b), "Inflexão na abordagem genealógica da modernidade em Michel Foucault: do arcaísmo disciplinar à sociedade de segurança”. Revista Brasileira de Ciência Politica, 30: 275-314.

Simmel, Georg. (2006), Questões fundamentais de sociologia. Rio de Janeiro, Jorge Zahar.

SPENCER, Herbert. (1891), Essays: scientific, political \& speculative. Londres, Williams and Norgate. TAVolaro, Sergio. (2007), "Variações no interior de um discurso hegemônico? Sobre a tensão 'ação - estrutura' na sociologia contemporânea”. Teoria \& Pesquisa, 1 (XVI): 97-125.

Turner, Jonathan H. (1984), “Durkheim's and Spencer's principles of social organization: a theoretical note". Sociological Perspectives, 1 (27): 21-32.

VAndenberghe, Frederic. (2005), Associologias de Georg Simmel. Bauru/Belém, Edusc/EdufPA. Weber, Max. (2004), A ética protestante e o "espírito" do capitalismo. São Paulo, Companhia das Letras.

WEBER, Max. (2016), Ética econômica das religiôes mundiais: ensaios comparados de sociologia da religião. Petrópolis, Vozes. 


\section{Resumo}

Indiferenciação por diferença: implicações da governamentalidade neoliberal para a teoria sociológica

Buscamos realizar uma leitura do conceito de governamentalidade neoliberal e suas ressonâncias em conceitos como sociedade de controle e novo espírito do capitalismo, como uma modulação específica de crítica ao enunciado da autonomização das esferas sociais. Diferente de uma crítica a esse enunciado que aponta para um processo de indiferenciação por identidade, levado a cabo pelo domínio da racionalidade instrumental, percebemos, a partir do Nascimento da Biopolítica, um diagnóstico do contemporâneo como perpassado por uma dinâmica de indiferenciação por diferença, operado por práticas e discursos que induzem a uma diferenciação crescente dos sujeitos, porém enquadrados sob o modelo do empresário de si e do capital humano.

Palavras-chave: Autonomização; Indiferenciação; Governamentalidade neoliberal; Empresário de si; Capital humano.

\section{Abstract}

Undifferentiation by difference: implications of neoliberal governmentality for sociological theory We seek to make a reading of the concept of neoliberal governmentality and its resonances in concepts such as society of control and new spirit of capitalism, as a specific modulation of the critique to the statement of the autonomization of social spheres. Unlike a critique of this statement that points to a process of undifferentiation by identity, carried out by the dominance of instrumental rationality, we perceive, from the Birth of Biopolitics, a diagnosis of the contemporary as perpassed by a dynamic of undifferentiation by difference, operated by practices and discourses that induce an increasing differentiation of the subjects, but framed under the model of the entrepreneur of the self and human capital.

Keywords: Autonomization; Undifferentiation; Neoliberal governmentality; Entrepreneur of the self; Human capital.

Texto recebido em 24/2/2019 e aprovado em 30/5/2019.

DOI: $10.11606 / 0103-2070 . t s .2020 .155166$.

Lucas Trindade da Silva é professor adjunto do Humanitas - Instituto de Estudos Integrados da Universidade Federal do Rio Grande do Norte (UfRN) e doutor em sociologia pela Universidade de Brasília (UnB).E-mail: lucastrindadedasilva@yahoo.com.br. 